\title{
A REPUTAÇÃO DAS EMPRESAS
}

O tema reputação corporativa tem ganhado destaque entre estudiosos da Administração. Várias são as correntes teóricas defendidas, cada qual com suas métricas e sugestões sobre o modo de gerenciar a reputação para produzir um efeito positivo no desempenho da empresa, ou mesmo evitar crises que comprometam sua sobrevivência. As principais correntes teóri- cas estão representadas nos livros indicados abaixo, lembrando que imagem e identidade organizacional são conceitos em geral tratados em associação com a reputação. Eliane P. Zamith Brito, professora do Programa de Pós-Graduação em Administração de Empresas da Universidade Presbiteriana Mackenzie, recomenda as seguintes obras:

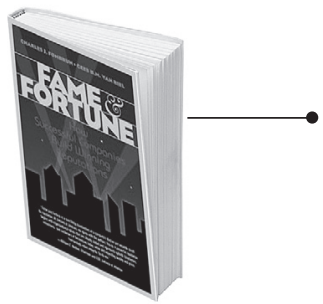

FAME AND FORTUNE: How Successful Companies Build Winning Reputations. Charles J. Fombrun e Cess van Riel. New York: FT Press, 2003. 304 p.

A obra possibilita que não acadêmicos compreendam o efeito da reputação sobre o desempenho da organização e como é possível gerenciá-la. Os autores apresentam as seis dimensões práticas que precisam ser gerenciadas pela organização no intuito de ter uma boa reputação. Ainda são caracterizados outros aspectos considerados relevantes para uma boa reputação. O uso de exemplos e ilustrações facilita a leitura e dá credibilidade ao conteúdo.
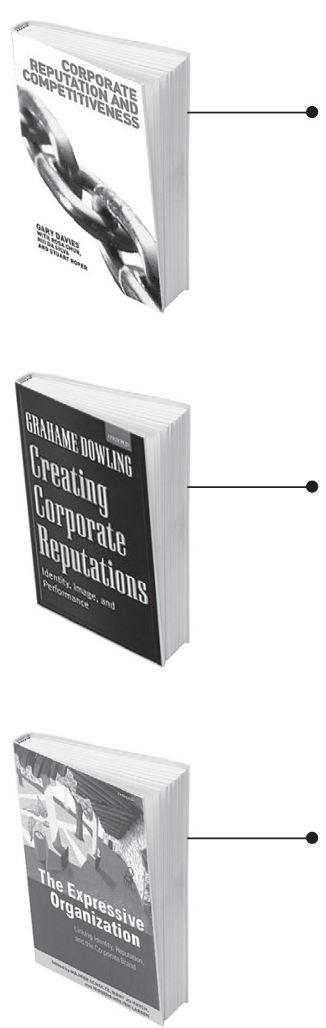

THE EXPRESSIVE ORGANIZATION: Linking Identity, Reputation, and the Corporate Brand. Majken Schultz, Mary Jo Hatch e Mogens Holten Larsen (Eds.). Oxford: Oxford University Press, 2000. 292 p.

O livro é uma interessante coletânea de artigos de diversos autores notáveis que têm experiências distintas. Os artigos versam sobre reputação e outros temas relacionados com sua capacidade de se auto-expressar e a seu propósito. Essa expressividade, segundo os autores, ocorre tanto interna como externamente à empresa.

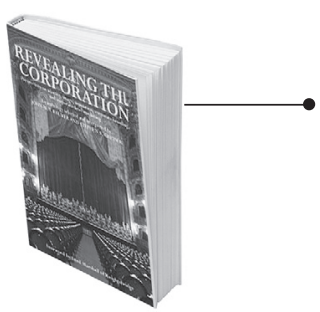

CORPORATE REPUTATION AND COMPETITIVENESS. Gary Davies et al. London: Routledge, 2003. 273 p.

A obra apresenta uma rápida revisão de estratégia e dos modelos de reputação, para depois introduzir a sua cadeia de reputação corporativa. Nessa visão de cadeia, os autores integram a dimensão interna da empresa à externa, e discutem a relação da imagem e da identidade com a reputação. Para eles, a reputação pode ser entendida e medida como a personalidade da empresa. A obra é complementada com estudos de caso que ilustram a mensuração da reputação e o seu efeito no desempenho organizacional.

CREATING CORPORATE REPUTATIONS: Identity, Image, and performance. Grahame Dowling. Oxford: Oxford University Press, 2002. 299 p.

O autor fornece uma visão geral sobre reputação, desde uma definição do conceito, passando pelos fatores que afetam as reputações e chegando à gestão das reputações da organização. Esta última parte é interessante, pois discute uma proposta de mensuração da reputação, mudança corporativa e o papel da comunicação e da reputação na gestão de crise na organização.

REVEALING THE CORPORATION: Perspectives on Identity, Image, Reputation, Corporate Branding, and Corporate-Level Marketing. John M. T. Balmer e Stephen A. Greyser (Eds.). London: Routledge, 2003. 365 p.

A obra é uma excelente coletânea de artigos clássicos e atuais sobre os temas reputação, identidade, imagem, marca e comunicação corporativa. Os autores fizeram um interessante e valioso trabalho de discussão introdutória sobre cada tema e comentários sobre os artigos. O resultado é um livro importante para os que estudam esses temas ou para aqueles que estão nas empresas tratando de questões estratégicas relacionadas com o desenvolvimento da organização. 